\title{
(2) OPEN ACCESS \\ Prehospital management of exertional heat stroke at sports competitions: International Olympic Committee Adverse Weather Impact Expert Working Group for the Olympic Games Tokyo 2020
}

\author{
Yuri Hosokawa (10, ', Sebastien Racinais 다, ${ }^{2}$ Takao Akama 다, ${ }^{1}$ David Zideman, ${ }^{3}$ \\ Richard Budgett, ${ }^{4}$ Douglas J Casa (1) , ${ }^{5}$ Stéphane Bermon, ${ }^{6,7}$ \\ Andrew J Grundstein (1) , ${ }^{8}$ Yannis P Pitsiladis (1) , ${ }^{9}$ Wolfgang Schobersberger (1) , ${ }^{10}$ \\ Fumihiro Yamasawa (1) ${ }^{11}$
}

- Additional supplemental material is published online only. To view, please visit the journal online (http://dx.doi. org/10.1136/bjsports-2020 103854)

For numbered affiliations see end of article.

Correspondence to Dr Yuri Hosokawa, Faculty of Sport Sciences, Waseda University, Tokorozawa 3591192, Japan;

yurihosokawa@waseda.jp

Accepted 8 April 2021
Check for updates

(c) Author(s) (or their employer(s)) 2021. Re-use permitted under CC BY-NC. No commercial re-use. See rights and permissions. Published by BMJ.

To cite: Hosokawa Y Racinais S, Akama T, et al. Br J Sports Med Epub ahead of print: [please include Day Month Year]. doi:10.1136/ bjsports-2020-103854

\section{ABSTRACT \\ Objectives This document aimed to summarise the key components of exertional heat stroke (EHS) prehospital management. \\ Methods Members of the International Olympic Committee Adverse Weather Impact Expert Working Group for the Olympic Games Tokyo 2020 summarised the current best practice regarding the EHS prehospital management.}

Results Sports competitions that are scheduled under high environmental heat stress or those that include events with high metabolic demands should implement and adopt policy and procedures for EHS prehospital management. The basic principles of EHS prehospital care are: early recognition, early diagnosis, rapid, on-site cooling and advanced clinical care. In order to achieve these principles, medical organisers must establish an area called the heat deck within or adjacent to the main medical tent that is optimised for EHS diagnosis, treatment and monitoring. Once admitted to the heat deck, the rectal temperature of the athlete with suspected EHS is assessed to confirm an elevated core body temperature. After EHS is diagnosed, the athlete must be cooled on-site until the rectal temperature is below $39^{\circ} \mathrm{C}$. While cooling the athlete, medical providers are recommended to conduct a blood analysis to rule out exercise-associated hyponatraemia or hypoglycaemia, provided that this can be safely performed without interrupting cooling. The athlete is transported to advanced care for a full medical evaluation only after the treatment has been provided on-site.

Conclusions A coordination of care among all medical stakeholders at the sports venue, during transport, and at the hospital is warranted to ensure effective management is provided to the EHS athlete.

\section{INTRODUCTION}

Exertional heat stroke (EHS) is an emergency condition that is defined by exercise-induced hyperthermia (generally $\geq 40.5^{\circ} \mathrm{C}$ core body temperature) associated with central nervous system (CNS) dysfunction (eg, disorientation, confusion, aggressiveness, hysteria, delirium, altered consciousness and irrational behaviour). ${ }^{1-4}$ EHS can affect the fittest athletes when their physiological capacity to dissipate metabolic heat production (related to exercise intensity) is challenged by environmental stress (eg, high temperature, high humidity, solar radiation and lack of wind flow) and/or intrinsic factors (eg, dehydration, excess motivation and recent illness). ${ }^{5}$ EHS should not be confused with heat exhaustion, which is defined as an inability to effectively continue exercise due to cardiovascular insufficiency, hypotension, energy depletion and central fatigue. ${ }^{2}$ While the incidence of heat exhaustion is greater than EHS, ${ }^{6}$ the condition can be managed by rest, body cooling, and rehydration, and the prognosis is benign. ${ }^{2}$ In contrast, prognosis from EHS can be lethal if appropriate prehospital care including cooling is not rapidly provided, prior to hospital transport. ${ }^{78}$

Previous studies from race medicine have reported $100 \%$ survival and approximately $93 \%$ of EHS patients discharged home on the day of collapse when they are cooled rapidly, within the first 30 min of collapse, using whole-body cold water immersion on site (ie, prehospital). ${ }^{910}$ Contrarily, fatal EHS cases are reported to have used other cooling modalities with inadequate cooling rates, ${ }^{511}$ lack of immediate cooling ${ }^{12}$ or inadequate cooling (ie, transport to the hospital before confirming the drop in internal body temperature). ${ }^{13}$ Therefore, the coordination of care must be established well in advance of the competition day to execute the appropriate treatment seamlessly. ${ }^{14}$ To that end, the International Olympic Committee Adverse Weather Impact Expert Working Group for the Olympic Games Tokyo 2020 delineated the steps that should be taken to properly identify, treat, and manage athletes with suspected EHS using the unique context of the Olympic Games as an example. This document may be applied for other elite and mass participation events, such as national, continental, world championships, and professional sports competitions with the risk of EHS (eg, with high ambient temperature and/or humidity).

\section{PRINCIPLES}

The four basic principles of EHS prehospital care are: early recognition, early diagnosis, rapid, on-site cooling and advanced clinical care. At the medical tent, there should be a designated medical director, ideally an experienced physician who 


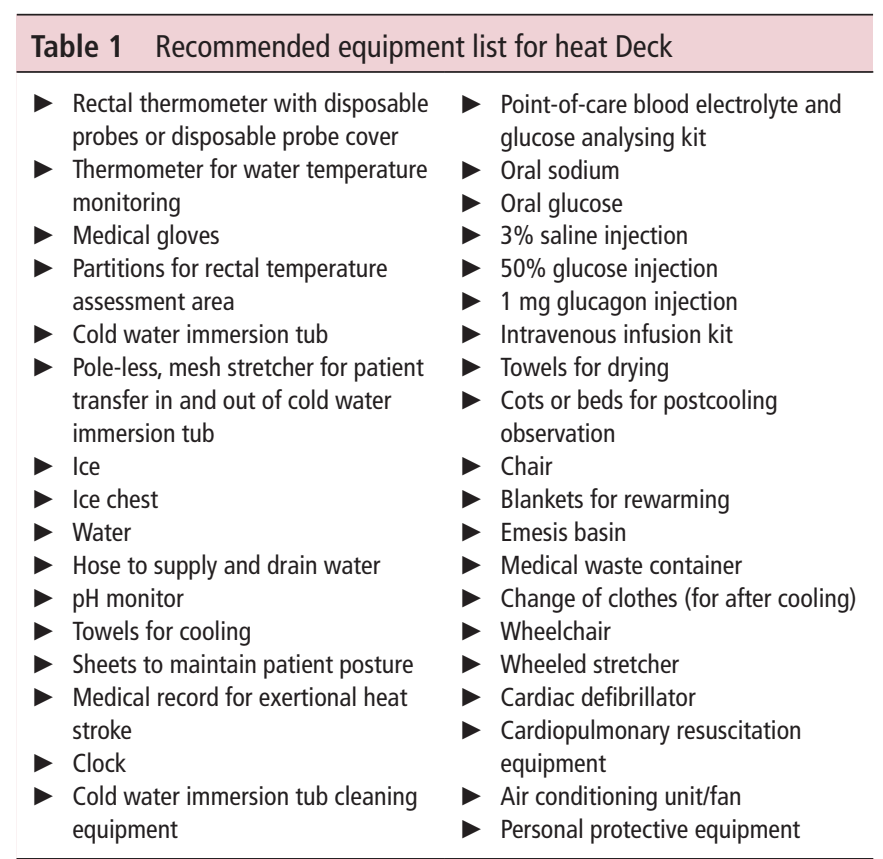

is familiar with event medical services and proficient in EHS prehospital management. Early recognition of EHS starts with educating medical personnel with a proper understanding of EHS and positioning these individuals on the field of play. When the competition takes place on a course (eg, marathon running, cycling), early coordination with the organisers is recommended to suggest a loop course so that the allocation of medical spotters can be concentrated and optimised. When EHS is suspected by medical spotters, the athlete is transferred to the venue medical tent and an early diagnosis confirmed by using a rectal thermometer to accurately measure the athlete's core body temperature. Furthermore, preparation of whole-body cold water immersion equipment will ensure that rapid, on-site cooling is applied to the patient prior to their hospital transfer. Lastly, communications with physicians at the designated receiving hospitals providing advanced clinical care should be preestablished to provide seamless follow on care of the patient. All of these steps will help to ensure that athletes suffering from EHS are cooled within the first $30 \mathrm{~min}$ of their collapse to effectively minimise the duration of excessive hyperthermia and that no subsequent sequela is missed. This document was created by the expert group as a general guideline for mass participation sporting events using the Olympic Games as an example. Therefore, although we have described the underlying principles, the specific policies and procedures may be subject to modification to meet the unique demands of each sport competition and individual national medical services.

\section{HEAT DECK SET-UP}

Events with a high risk of EHS (eg, athletics, beach volleyball, cycling, football, hockey, marathon swimming, modern pentathlon, rowing, rugby, tennis and triathlon), when scheduled under stressful environmental conditions must prepare a heat deck within or adjacent to the main athlete medical tent. It should be noted that in sports with a high metabolic demand (eg, marathon running), a heat deck set-up is still advised when the environmental condition is mild or cool. ${ }^{15}$ The heat deck is a designated area for EHS assessment and treatment; therefore, the area must be well marked so as not to be mistaken for part of the routine treatment area of the athlete medical tent. The

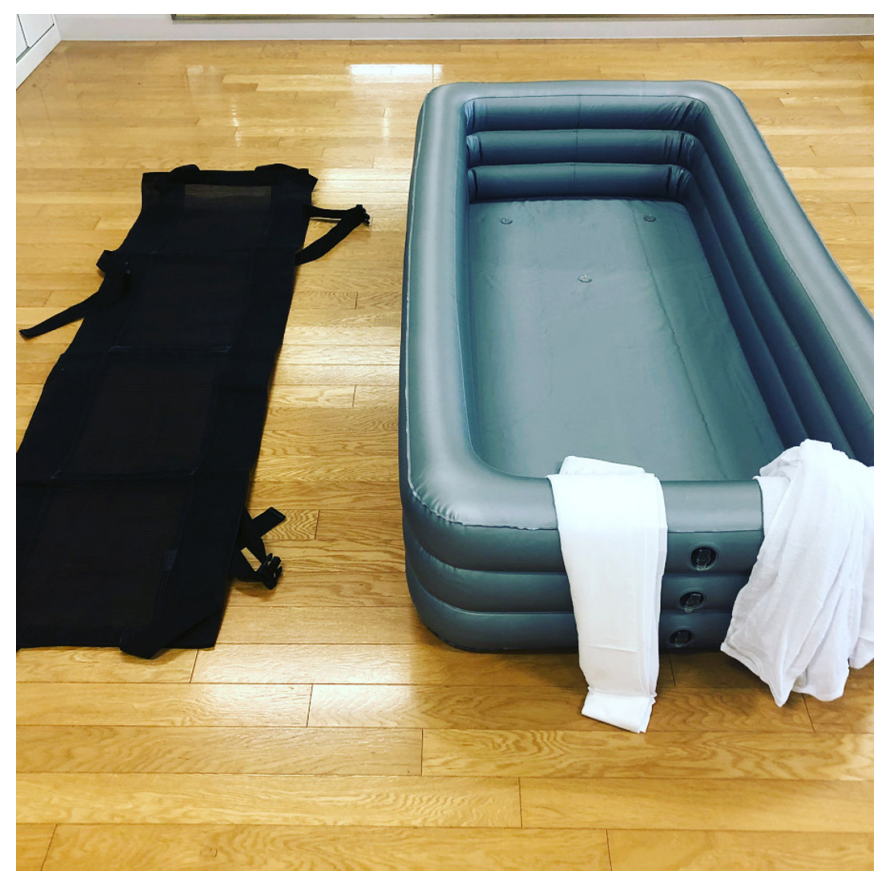

Figure 1 Example of a pole-less stretcher and a tub for cold water immersion (dimensions: $100 \mathrm{~cm} \times 200 \mathrm{~cm} \times 50 \mathrm{~cm}$ ).

heat deck must be prepared at a location which has access to a water source and water drainage, is protected from unnecessary attention from spectators and media, is easily accessed from the expected site of collapse (such as the alongside the field of play in team sports or near the finish line for individual sports) and has direct ambulance access/egress. Similar to the traditional medical tent, the Venue Medical Officer should implement an admission process to the heat deck using the appropriate accreditation system to limit the athlete's team staff and family members from entering the area freely. Ideally, the heat deck should be housed in an indoor facility with air conditioning and/ or a fan. If an indoor heat deck that meets these criteria cannot be established (ie, lack of water source and water drainage, lack of direct access from the field of play), the Venue Medical Officer may choose to set up a portable tent structure to more closely meet the requirements of a heat deck. The list of recommended equipment is summarised in table 1 . The quantity of each item depends on the total number of participants and the relative risk of EHS at the event (eg, environmental condition, exercise duration and exercise intensity). A thorough evaluation of local environmental conditions and exertional heat illness records from previous international and national competitions of a similar setup should be reviewed to make an informed estimate of amount of resources needed.

The heat deck can be divided into three sections: temperature assessment area, cold water immersion area and observation area. The temperature assessment area should have partitions to limit any unnecessary exposure of an athlete during rectal temperature measurement. If available, the athlete should be laid down on a pole-less mesh stretcher before measurement of their rectal temperature so that they can be transferred directly to the cold water immersion tub in the cold water immersion area once the thermometer probe has been inserted (figure 1). The observation area should have cots set up for athletes to rest until all their vital signs are within a predetermined normal range.

During the time of competition, cold water immersion tubs do not need to be drained and cleaned after each use if not obviously 


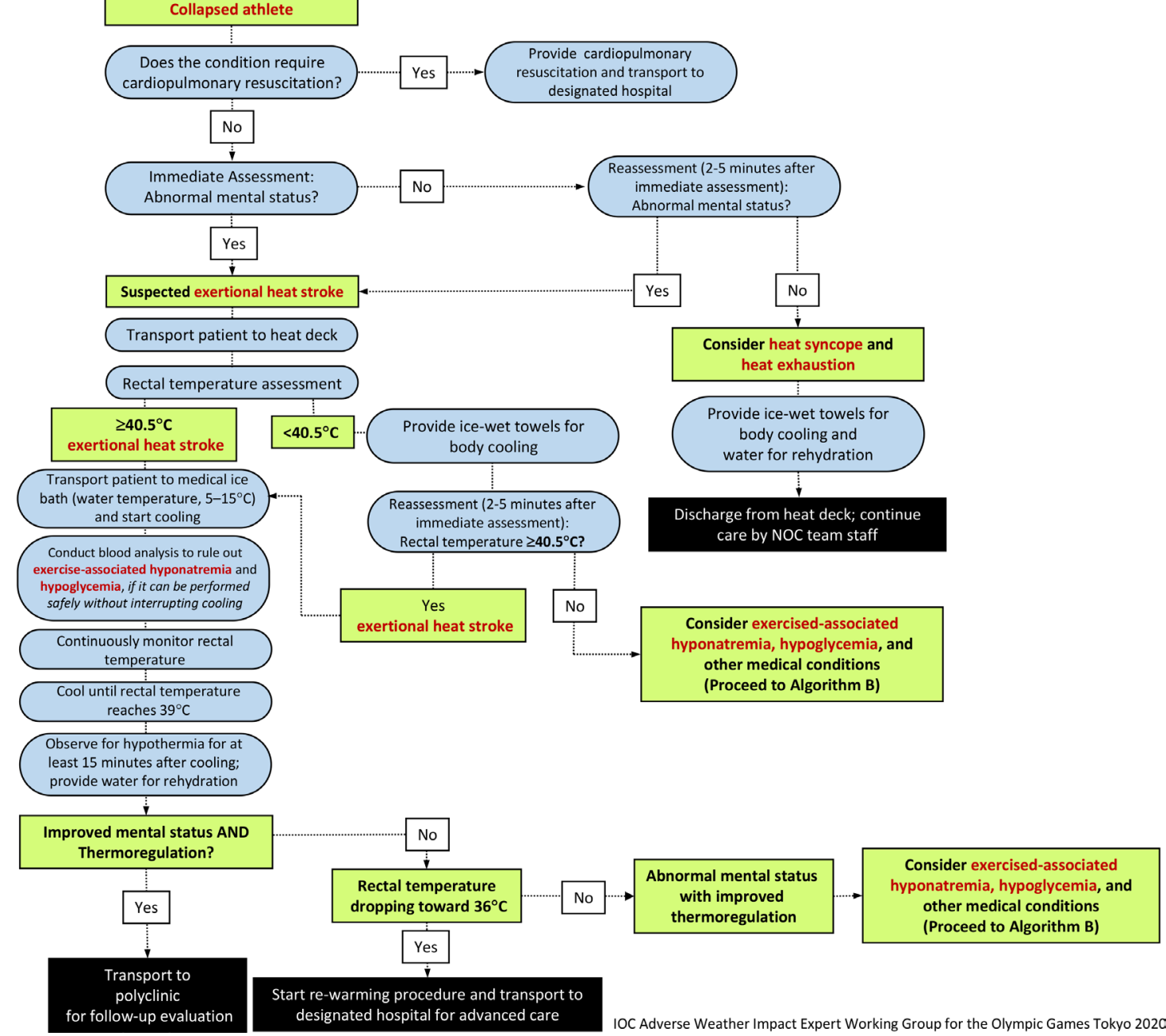

Figure 2 Algorithm (A) for the initial diagnosis and management of an athlete with suspected exertional heat stroke. NOC, National Olympic Committee.

contaminated. Contaminated cold water immersion tubs (ie, vomiting, diarrhoea and open wound) should be well labelled and not be reused for other athletes. These contaminated tubs must not be used until they have been fully cleaned and disinfected (online supplemental appendix 1). For multiday event, all tubs, including tubs without obvious contamination, must be fully cleaned, disinfected and dried at the end of each day of competition.

\section{PROCEDURES FOR BODY TEMPERATURE ASSESSMENT}

The medical procedures that should be followed by medical providers caring for EHS athletes are outlined in figures 2 and 3. Medical providers must wear gloves and appropriate personal protective equipment during all patient care activities.

Common clinical presentations of EHS may include: collapse, confusion, aggressiveness, hysteria, delirium, altered consciousness, irrational behaviour, irritability, seizures, dehydration, hyperthermia, diarrhoea, vomiting, dizziness, fatigue and weakness. Since a sudden collapse can also be the result of cardiac arrest, medical providers must first exclude any cardiac cause and then measure the rectal temperature to assess for EHS. While a rectal temperature above $40^{\circ} \mathrm{C}$ has previously been used as diagnostic criteria, ${ }^{16}$ several authors have identified that $40.5^{\circ} \mathrm{C}$ may be more specific for a diagnosis of EHS. ${ }^{1-4}$

Rectal temperature measurement is the only valid and practical method of core body temperature assessment to accurately diagnose athletes with EHS in the prehospital setting. ${ }^{1-3} 7$ A rectal thermometer with flexible, disposable probe $(2 \mathrm{~m}$ length) is recommended for patient comfort and ease of continuous monitoring throughout the treatment. The rectal thermometer should be inserted through the anal sphincter for at least $10 \mathrm{~cm}$. It is advised to mark the probe at the insertion length so that the thermometer is fully inserted to the required length. Depending on the local medical regulation, there may be a restriction as to who can conduct the rectal temperature assessment. For example, in the context of the Games of the XXXII Olympiad (Tokyo 2020), rectal temperature must be measured by a physician, or a nurse working under the supervision of a physician. In future Games in France (Paris 2024) and the USA (Los Angeles 2028), healthcare professionals who are trained to measure rectal temperatures can undertake this procedure (ie, no specific delineation of a particular medical license).

The athletes do not need to be totally undressed during the temperature treatment process. Tight athletic clothing (ie, swim suits) may be cut by the medical provider to obtain access to measure the rectal temperature. Personal protective sport equipment worn by the athlete (eg, field hockey goalkeeper) must be removed prior to whole-body cold water immersion. Only in rare circumstances where there is inability to remove this sport equipment, due to equipment breakdown or delayed recognition 


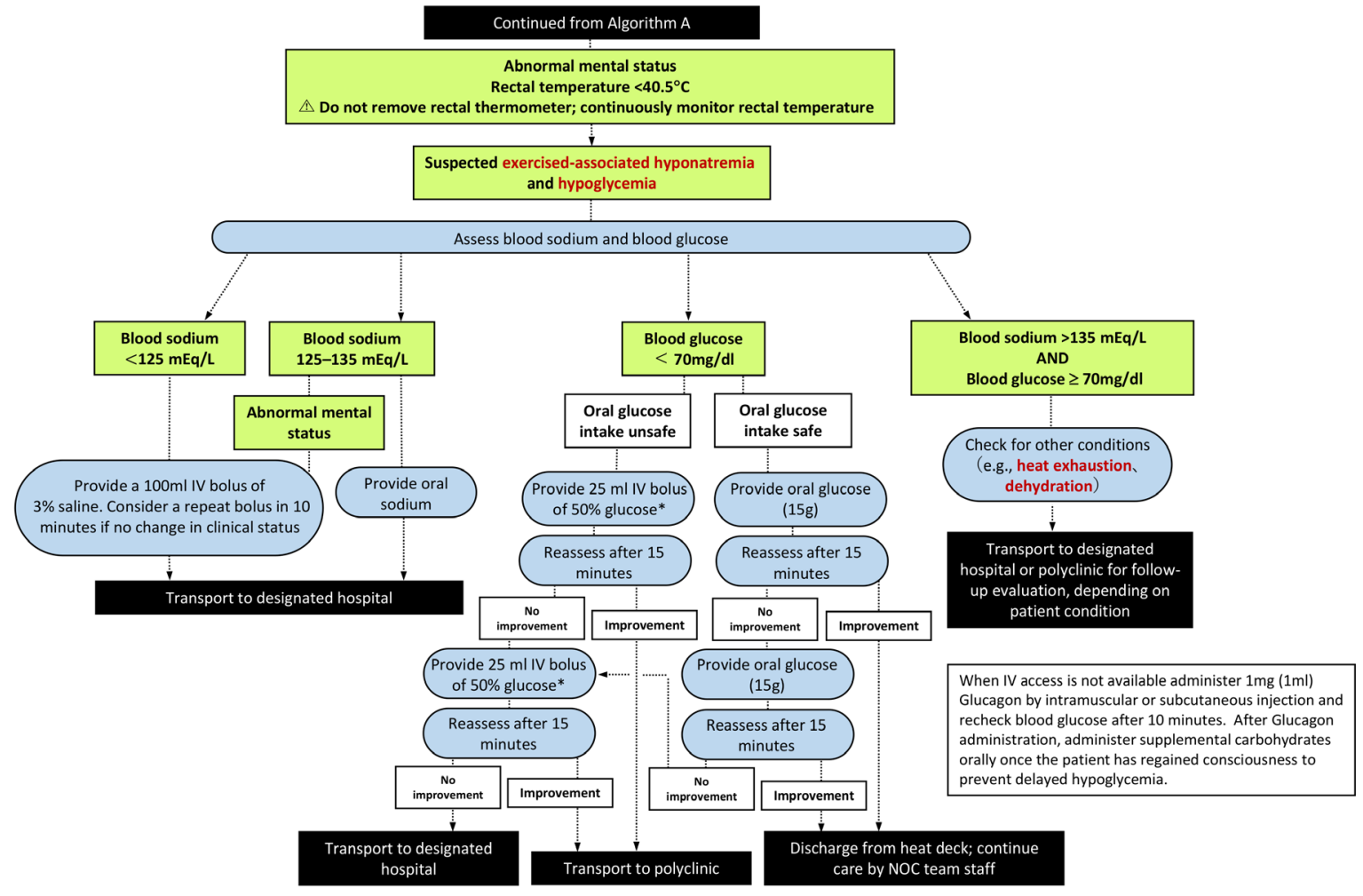

*Treating doctor must complete and submit a retroactive TUE for the patient

IOC Adverse Weather Impact Expert Working Group for the Olympic Games Tokyo 2020

Figure 3 Algorithm (B) for the management of an athlete with exertional heat stroke (continued from figure 2). When intravenous access is not available administer $1 \mathrm{mg}(1 \mathrm{~mL})$ Glucagon by intramuscular or subcutaneous injection and recheck blood glucose after 10 min. After Glucagon administration, administer supplemental carbohydrates orally once the patient has regained consciousness to prevent delayed hypoglycaemic. NOC, National Olympic Committee.

of the collapsed athlete, must the time to start cooling be prioritised over the removal of equipment and the athlete cooled wearing their equipment. ${ }^{17}$

It should be noted that clinical presentations indicative of CNS dysfunction may be delayed (eg, disorientation, confusion, aggressiveness, hysteria, delirium, altered level of consciousness and irrational behaviour). Collapsed athletes with confirmed hyperthermia below $40.5^{\circ} \mathrm{C}$ should still be cooled using the whole-body rotating ice-wet towel procedure where wet towels soaked in iced water are applied to the athlete and exchanged every 1-2 min (figure 4). Athletes who are suspected of EHS from their symptomology but have a rectal temperature measured at below $40.5^{\circ} \mathrm{C}$ should still continue to have their rectal temperature monitored continuously and undergo a blood sodium and blood glucose point-of-care analysis for the differential diagnosis of their medical condition (figure 3).

\section{PREHOSPITAL TREATMENT AT THE COLD WATER IMMERSION AREA}

Athletes with confirmed hyperthermia and CNS dysfunction should be cooled using whole-body cold water immersion. Cooling should continue until the rectal temperature reaches $<39^{\circ} \mathrm{C}$. The rate of cooling cannot be estimated from the initial body temperature result or from the body composition of the athlete. ${ }^{18}$ Therefore, the rectal temperature must be monitored continuously throughout the duration of the treatment, and continue until the body temperature has stabilised post cooling for at least $15 \mathrm{~min}$. Although many publications report a cooling rate in a linear manner to the ease of calculation and data presentation, it is common for the rectal temperature to plateau or even slightly increase during the first few minutes of the whole-body

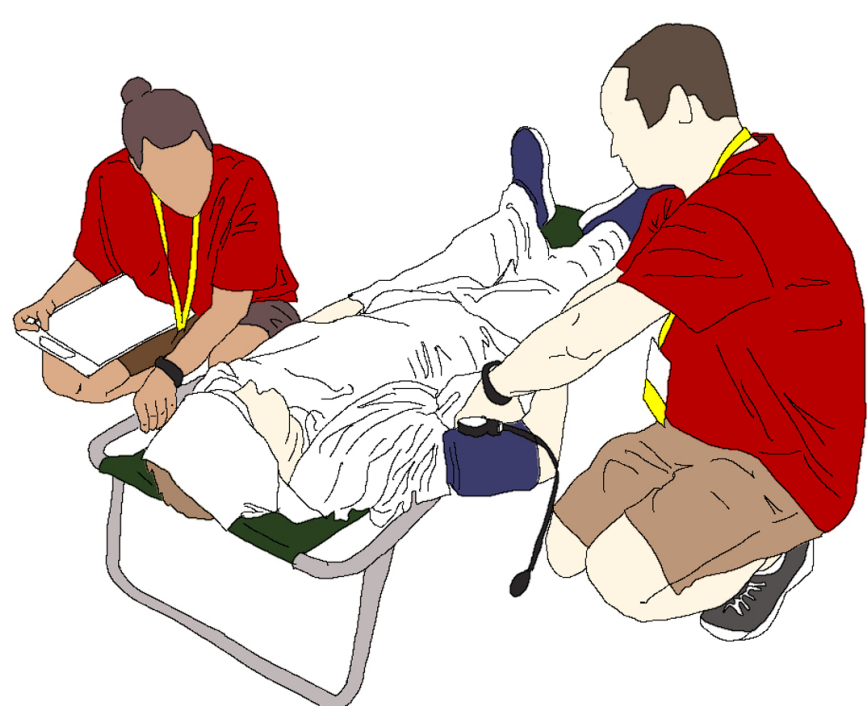

Figure 4 Whole-body rotating ice-wet towel requiring the application of towels soaked in ice water. Towels should be exchanged every 1-2 min to maintain cooling capacity. 


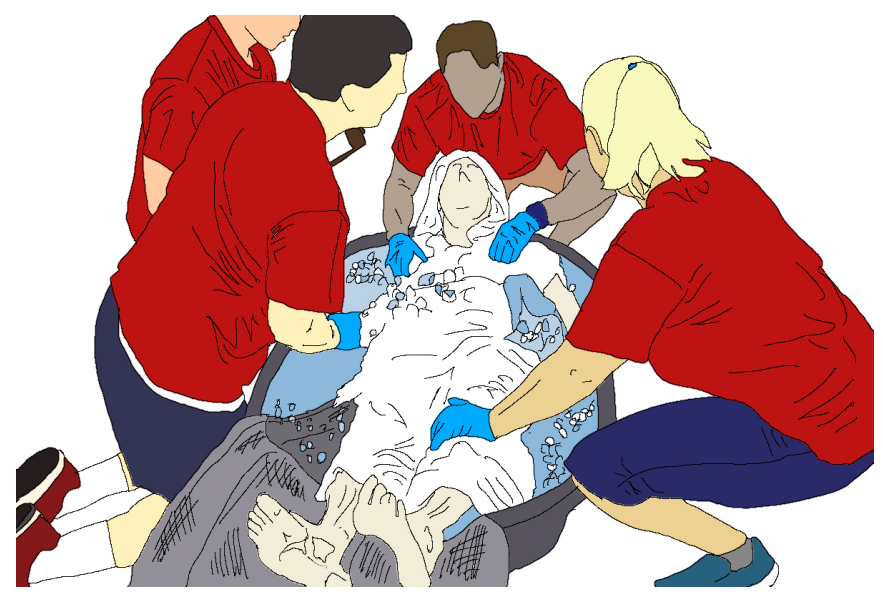

Figure 5 Exertional heat stroke treatment requires at least four trained medical providers per patient. The following roles should be assigned to individual medical personnel: $(A)$ maintaining airway and patient, (B) body (rectal) temperature monitoring, (C) continuously stirring and managing cold water immersion bath and (D) documentation of medical records. The dimension of the tub used in this figure is approximately $100 \mathrm{~cm} \times 150 \mathrm{~cm} \times 60 \mathrm{~cm}$, and holds $190 \mathrm{~L}$. When dealing with tall and/or large athlete, a larger tub should be considered (figure 1).

cold water immersion. ${ }^{19}$ This is due to an acute peripheral vasoconstriction redirecting warmer blood from the cutaneous tissues to the core.

The ice bath should be filled with water and ice (1/2-2/3 full) prior to the start of the sport event. The water temperature should remain between $5^{\circ} \mathrm{C}$ and $15^{\circ} \mathrm{C}$ and the volume of cold water must be enough to submerge as much of the body surface area as possible by prioritising submersion of the torso. Safe and effective EHS treatment will require at least four trained medical providers (Provider A-D) per athlete. Provider $\mathrm{A}$ is in charge of maintaining the airway and upright posture of the patient; Provider B is in charge of monitoring the core temperature; Provider $\mathrm{C}$ is responsible for continuously stirring the cold water immersion bath; and Provider D ensures that all medical records are properly documented (figure 5). Online supplemental appendix 2 provides a sample template of an EHS specific medical record that may be used on the heat deck. The four-person team is the minimal number of personnel required. Additional volunteers may be required to safely carry large and/or combative patients. For international competitions, it is advised that the members of the host medical team who are fluent in languages other than their native language are used to staff the heat deck.

While cooling the athlete, conduct a blood analysis to rule out exercise-associated hyponatraemia or hypoglycaemia, provided that this can be safely performed without interrupting cooling (figure 2). Immersion should continue until the rectal temperature reaches $39^{\circ} \mathrm{C}$. The athlete should then be removed from the cold-water bath, dried and rested in a cool environment under medical supervision. The athlete's rectal temperature must continue to be monitored to ensure that the fall in core temperature fall has been maintained. If the core temperature starts to rise again then the individual should be returned to the coldwater bath and the cooling procedure repeated until a constant temperature $<39^{\circ} \mathrm{C}$ is maintained.

If the athlete starts to show a rapid drop toward $36^{\circ} \mathrm{C}$ after removal from cold water immersion during the 15 -minute postcooling recovery period, they should be dried, their wet clothing removed, and insulated blankets used until they can be transported to the designated hospital for rewarming and advanced care. If privacy can be maintained, moving the athlete into direct sunlight may assist with rewarming while waiting for the ambulance.

In circumstances where athletes may collapse due to EHS at remote locations from the heat deck (ie, marathon running and cycling), organisers should also consider preparing a tarp-assisted cooling (TACo). ${ }^{20}$ In TACo, the athlete is laid down supine on a waterproof tarp and is repositioned by a medical provider to a semireclining position by slightly lifting the tarp on the side of the athlete's head. Additional providers lift the other sides of the tarp so that when ice and water is poured on to the athlete they can be contained within the tarp and create an environment that resembles whole-body cold water immersion. When using this method, venous access to conduct blood analysis may be unrealistic.

\section{POST-TREATMENT FOLLOW-UP}

All athletes diagnosed with EHS must be cooled first and transported second. Once a stable postcooling core body temperature has been confirmed for at least $15 \mathrm{~min}$, the medical team should initiate the referral process to transport the athlete to hospital using the on-site emergency medical services. Athletes who have been treated for EHS must be transported to the designated athlete hospital for a follow-up evaluation. At the hospital, the duty physician should undertake a full medical evaluation including but not limited to: a general physical examination, cognitive testing (ie, anterograde and retrograde amnesia), blood tests (eg, markers of renal, hepatic and musculoskeletal damage) and further core temperature monitoring. The decision to discharge the athlete can be made by the hospital physician, whereas the decision to return to competition should be made by the athlete's Team Physician guided by advice from the hospital and event medical teams.

\section{SPECIAL CONSIDERATIONS FOR INFECTIOUS CONTROL DURING CORONAVIRUS PANDEMIC}

The coronavirus pandemic has posed new challenges to medical personnel when considering the risks of SARS-CoV-2 transmission while caring for EHS athletes. The advice on personal protective equipment and aerosol generating procedures is rapidly changing as the pandemic progresses. ${ }^{21}$ Medical personnel stationed at the heat deck are advised to follow the recommended local infection control measures, such as donning personal protective equipment (eg, sleeves, apron, gloves and a medical grade face mask) and social distancing of medical personnel who are not assigned to treat EHS athletes. ${ }^{22}$ Currently, bathing water has not been reported as a SARS-CoV-2 transmission medium ${ }^{23}$; however, instruments (eg, cold water immersion tub and pole-less mesh stretcher) used during the EHS treatment procedure are not exempt from the risk of contamination. Therefore, where there is a known risk of coronavirus infection, local protocols must be followed and a more vigorous cleaning of these non-consumable items of equipment may be required. Lastly, medical providers should be reminded to follow the general rule of triage to prioritise the assessment and treatment of the condition that require more immediate attention to increase the chance of survival (eg, sudden cardiac arrest $>$ EHS $>$ suspected SARS-CoV-2 infection). 


\section{LIMITATION}

The expert working group recognise that these recommendations may not be suitable for Paralympic athletes where there may be specific physiological considerations and the use of particular moving and handling techniques in the management process. While the reported incidence rate of exertional heat illness is low among Paralympic athletes, ${ }^{24}$ their thermoregulatory risk and management of heat strain require special attention. ${ }^{25}$ Sporting events with Paralympic athletes should explore classification specific EHS management strategies to safely and effectively cool these athletes.

\section{CONCLUSION}

Maximising survival and minimising sequela from EHS requires following basic principles: early recognition, early diagnosis, rapid, on-site cooling and advanced clinical care. This requires the close coordination of all medical stakeholders who are providing care at a sports venue, during transport and at hospital. It is recommended that a thorough review of the EHS medical protocols together with hands-on scenario training should be carried out with all the medical staff prior to competition.

\section{What are the new findings?}

- The current document outlines the steps that should be taken to properly identify, treat and manage athletes with suspected exertional heat stroke (EHS) using the unique context of an elite, large-scale sports competition as an example.

- A designated area for EHS assessment and treatment should be established to ensure that all athletes diagnosed with EHS are cooled first before being transported to the hospital for a follow-up evaluation.

- A rectal temperature probe should be available for the primary diagnosis of EHS. A point-of-care blood analysis device should be available to conduct blood sodium and blood glucose analysis for a differential diagnosis of the collapsed athlete's medical condition.

\section{How might it impact on clinical practice in the near}

\section{future?}

- The chief medical officer of mass participation events may implement the algorithms presented in the current document as part of the policy and procedures for exertional heat stroke (EHS) prehospital management.

- While rigorous infection prevention measures should be implemented, general processes required for the prehospital management of EHS can be considered a low risk for aerosol transmission. Medical providers should be reminded to follow the general rules of triage to prioritise the assessment and treatment of athletes that require more immediate attention to increase the chance of survival (eg, sudden cardiac arrest $>$ EHS $>$ suspected SARS-CoV-2 infection).

\section{Author affiliations}

Faculty of Sport Sciences, Waseda University, Tokorozawa, Japan

${ }^{2}$ Research and Scientific Support Department, Aspetar Qatar Orthopaedic and Sports Medicine Hospital, Doha, Qatar

${ }^{3}$ Medical and Scientific Commission Games Group, International Olympic Committee, Lausanne, Switzerland

${ }^{4}$ Medical and Scientific Department, International Olympic Committee, Lausanne, Switzerland
${ }^{5}$ Korey Stringer Institiute, Department of Kinesiology, University of Connecticut,

Storrs, Connecticut, USA

${ }^{6} \mathrm{Health}$ and Science Department, World Athletics, Monaco

${ }^{7}$ LAMHESS, Université Côte d'Azur, Nice, France

${ }^{8}$ Department of Geography, University of Georgia, Athens, Georgia, USA

${ }^{9}$ Collaborating Centre of Sports Medicine, University of Brighton, Eastbourne, UK

${ }^{10}$ Insitute for Sports Medicine, Alpine Medicine and Health Tourism, University for Health Sciences, Medical Informatics and Technology (UMIT), Hall, Austria

${ }^{11}$ Marubeni Health Promotion Center, Marubeni Corporation, Chuo-ku, Japan

\section{Twitter Sebastien Racinais @ephysiol}

Acknowledgements The authors thank Dr Marie-Elaine Grant and Dr Brian McCloskey for their assistance in preparing the paper.

Contributors YH contributed to the conception of the work. All authors contributed in drafting or revising the manuscript and approval of final version to be published.

Funding The authors have not declared a specific grant for this research from any funding agency in the public, commercial or not-for-profit sectors.

Competing interests All authors are members of the International Olympic Committee Adverse Weather Impact expert working Group for the Olympic Games Tokyo 2020; not receiving honorarium.

\section{Patient consent for publication Not required.}

Provenance and peer review Not commissioned; externally peer reviewed.

Data availability statement Data sharing not applicable as no datasets generated and/or analysed for this study.

Supplemental material This content has been supplied by the author(s). It has not been vetted by BMJ Publishing Group Limited (BMJ) and may not have been peer-reviewed. Any opinions or recommendations discussed are solely those of the author(s) and are not endorsed by BMJ. BMJ disclaims all liability and responsibility arising from any reliance placed on the content. Where the content includes any translated material, BMJ does not warrant the accuracy and reliability of the translations (including but not limited to local regulations, clinical guidelines, terminology, drug names and drug dosages), and is not responsible for any error and/or omissions arising from translation and adaptation or otherwise.

Open access This is an open access article distributed in accordance with the Creative Commons Attribution Non Commercial (CC BY-NC 4.0) license, which permits others to distribute, remix, adapt, build upon this work non-commercially, and license their derivative works on different terms, provided the original work is properly cited, appropriate credit is given, any changes made indicated, and the use is non-commercial. See: http://creativecommons.org/licenses/by-nc/4.0/.

\section{ORCID iDs}

Yuri Hosokawa http://orcid.org/0000-0001-9138-5361

Sebastien Racinais http://orcid.org/0000-0003-0348-4744

Takao Akama http://orcid.org/0000-0002-3937-2448

Douglas I Casa http://orcid.org/0000-0002-8858-2636

Andrew J Grundstein http://orcid.org/0000-0002-0574-6253

Yannis P Pitsiladis http://orcid.org/0000-0001-6210-2449

Wolfgang Schobersberger http://orcid.org/0000-0002-5657-0307

Fumihiro Yamasawa http://orcid.org/0000-0001-6315-8479

\section{REFERENCES}

1 Belval LN, Casa DJ, Adams WM, et al. Consensus Statement- prehospital care of exertional heat stroke. Prehosp Emerg Care 2018;22:392-7.

2 Casa DJ, DeMartini JK, Bergeron MF, et al. National athletic trainers' association position statement: exertional heat illnesses. J Ath/ Train 2015;50:986-1000.

3 Mears S, Watson P. IIRM medical care manual. Norfolk: International Institute for Race Medicine, 2015.

4 Epstein Y, Yanovich R. Heatstroke. N Eng/ J Med 2019;380:2449-59.

5 Rav-Acha M, Hadad E, Epstein Y, et al. Fatal exertional heat stroke: a case series. Am J Med Sci 2004;328:84-7.

6 Stearns RL, Hosokawa Y, Adams WM. Repeated exertional heat stroke incidence in a warm-weather road race. J Athl Train 2017;52:S106.

7 Hosokawa Y, Nagata T, Hasegawa M. Inconsistency in the standard of Care-Toward evidence-based management of exertional heat stroke. Front Physiol 2019;10:108.

8 Grundstein A, Knox JA, Vanos J, et al. American football and fatal exertional heat stroke: a case study of Korey Stringer. Int J Biometeorol 2017;61:1471-80.

9 Hawes R, McMorran J, Vallis C. Exertional heat illness in half marathon runners: experiences of the great North run. Emerg Med J 2010;27:866-7.

10 Demartini JK, Casa DJ, Stearns R, et al. Effectiveness of cold water immersion in the treatment of exertional heat stroke at the Falmouth road race. Med Sci Sports Exerc 2015;47:240-5. 
11 Filep EM, Murata Y, Endres BD, et al. Exertional heat stroke, modality cooling rate, and survival outcomes: a systematic review. Medicina 2020;56:589.

12 Stearns RL, Casa DJ, O'Connor FG, et al. A tale of two heat strokes: a comparative case study. Curr Sports Med Rep 2016;15:94-7.

13 Hosokawa Y, Stearns RL, Casa DJ. Is heat intolerance state or trait? Sports Med 2019;49:365-70.

14 Adams WM, Hosokawa Y, Troyanos C. Organization and execution of on-site health care during a mass participation event. Athletic Train Sports Health Care 2018;10:101-4.

15 Roberts WO. Determining a "do not start" temperature for a marathon on the basis of adverse outcomes. Med Sci Sports Exerc 2010;42:226-32.

16 Bouchama A, Knochel JP. Heat stroke. N Eng/ J Med 2002;346:1978-88.

17 Miller KC, Long BC, Edwards J. Necessity of removing American football Uniforms from humans with hyperthermia before cold-water immersion. J Athl Train 2015:50:1240-6.

18 Poirier MP, Notley SR, Flouris AD, et al. Physical characteristics cannot be used to predict cooling time using cold-water immersion as a treatment for exertional hyperthermia. Appl Physiol Nutr Metab 2018;43:857-60.
19 Hosokawa Y, Casa DJ, Racinais S. Translating evidence-based practice to clinical practice in Tokyo 2020: how to diagnose and manage exertional heat stroke. Br J Sports Med 2020;54:883-4.

20 Hosokawa Y, Adams WM, Belval LN, et al. Tarp-Assisted cooling as a method of whole-body cooling in hyperthermic individuals. Ann Emerg Med 2017;69:347-52.

21 Kramer DB, Lo B, Dickert NW. CPR in the Covid-19 era — an ethical framework. N Engl J Med Medicine 2020;383:e6.

22 Hodgson L, Phillips G, Gordon J, et al. Interassociation consensus recommendations for pitch-side emergency care and personal protective equipment for elite sport during the COVID-19 pandemic. Br I Sports Med 2020. doi:10.1136/bjsports-2020-103226. [Epub ahead of print: 24 Dec 2020].

23 World Health Organization, United Nations Children's Fund. Water, sanitation, hygiene, and waste management for SARS-CoV-2, the virus that causes COVID-19, 2020. Available: https://www.who.int/publications-detail-redirect/WHO-2019-nCoVIPC-WASH-2020.4 [Accessed 8 Nov 2020].

24 Zhang Y, Bishop PA. Risks of heat illness in athletes with spinal cord injury: current evidence and needs. Front Sports Act Living 2019;1:68.

25 Griggs KE, Stephenson BT, Price MJ, et al. Heat-related issues and practical applications for Paralympic athletes at Tokyo 2020. Temperature 2020;7:37-57. 